\title{
Validating the Staff Satisfaction Index and the Happy Career for In-Service Firefighters
}

\author{
Rosnah Ismail (D), ${ }^{1}$ Nor Hisham Mohammad, ${ }^{2}$ Ashrul Riezal Asbar, \\ Ismail Abdul Ghani, ${ }^{2}$ and T. Ramayah $\mathbb{1 D}^{3,4,5,6,7}$ \\ ${ }^{1}$ Community Health Department, Faculty of Medicine, Universiti Kebangsaan Malaysia, Jalan Yaacob Latiff 56000 Cheras, \\ Kuala Lumpur, Malaysia \\ ${ }^{2}$ Headquarters Fire and Rescue Department of Malaysia, Lebuh Wawasan, Presint 7, Putrajaya 62250, Malaysia \\ ${ }^{3}$ School of Management, Universiti Sains Malaysia, Minden 11800, Penang, Malaysia \\ ${ }^{4}$ Daffodil International University, Dhaka, Bangladesh \\ ${ }^{5}$ Faculty of Economics and Business, Universiti Malaysia Sarawak (UNIMAS), Kota Samarahan, Malaysia \\ ${ }^{6}$ Fakulti Ekonomi dan Pengurusan (FEP), Universiti Kebangsaan Malaysia (UKM), Bangi, Malaysia \\ ${ }^{7}$ Fakulti Pengurusan dan Perniagaan, Universiti Teknologi MARA (UiTM), Shah Alam, Malaysia
}

Correspondence should be addressed to T. Ramayah; ramayah@usm.my

Received 28 September 2021; Accepted 13 January 2022; Published 8 March 2022

Academic Editor: Carol J. Burns

Copyright (C) 2022 Rosnah Ismail et al. This is an open access article distributed under the Creative Commons Attribution License, which permits unrestricted use, distribution, and reproduction in any medium, provided the original work is properly cited.

This study aims at validating the Staff Satisfaction Index (SSI) and the Happy Career (HC) scale for in-service firefighters. The SSI consists of two dimensions, namely, protection against hazards at work and welfare, with 16 subdimensions. A total of 6970 data points were collected via the Internet. Both dimensions of the SSI were regressed on the HC scale using partial least square structural equation modelling. The dimensions satisfied all measurements and structural model assessments. Protection against hazards at work $(\beta=0.370, p<0.001)$ and welfare $(\beta=0.375, p<0.001)$ explained $46.6 \%$ of the happiness variance. Both dimensions displayed small-to-medium effect sizes and relevance to predicting happiness $\left(Q^{2}=0.339\right)$. Implications of the findings are discussed further.

\section{Introduction}

Firefighter's duties are unique and unpredictable, depending on their assigned tasks in an undetermined work environment in times of crisis. Therefore, firefighter's satisfaction and feelings of happiness while performing their duties are worth exploring as a platform for continuous improvement in managing employee safety, health, and welfare issues. The typical employee satisfaction questionnaire is not suitable to be administered to firefighters because the developed items are generic and lack transcultural adaptation for in-service firefighters. Therefore, a tailor-made tool to measure the firefighter's level of satisfaction and happiness at work is needed.

Developing a satisfaction and happiness tool is critical for understanding the firefighter's cognitive, emotional, and physical views/experiences and the work environment they interact with. Protection against safety hazards at work and the provision of welfare frequently emerge as important factors based on various shared experiences pertaining to their tasks. For example, wearing full gear while engaged in firefighting activities to protect them against hazardous chemicals arising from the combustion of on-site materials. To wear full gear, one must be physically and mentally fit to ensure the heavy equipment does not cause harm while handling other heavy firefighting equipment. Wearing full gear and hauling hoses during the fire response requires $42.77 \mathrm{ml} / \mathrm{kg} / \mathrm{min}$ of oxygen consumption [1]. This demands high cardiovascular endurance and mental resilience, especially when the time to task completion is prolonged. Like employees in other organizations, firefighters seek recognition. Rewards for firefighters who do a good job include 
salary and special allowances, career advancement, injury compensation, and an organizational climate that takes care of their needs.

The pooling and creating of satisfaction measurement items (Table 1) were guided by the Occupational Safety and Health Act of 1994 [2]. Two theoretical models (i.e., Maslow's hierarchy of needs, as explained by a contemporary researcher [3] and Herzberg's motivator-hygiene theory [4]) and experiential input from firefighters were used. The items were adopted from the Job Descriptive Index (JDI) [5] to measure the staff's job satisfaction. Originally, the JDI was a "facet" measure of job satisfaction, meaning that respondents are asked to think about specific facets of their job, such as coworkers, the work itself, pay, opportunities for promotion, and supervision. The respondents were asked to rate their satisfaction with these specific facets. However, our satisfaction measurement omitted teamwork among coworkers because of firefighters' strong bond in providing fire protection and suppression services and responding to other types of crises. Hence, this facet was considered inappropriate to include.

In view of the multidimensionality of the satisfaction measurement items, the cluster of items is an index rather than a simple scale giving one composite score-in this case, a satisfaction score. The index was called the Staff Satisfaction Index (SSI). A Happy Career (HC) scale was developed to measure positive emotions while performing assigned firefighter duties. Furthermore, the scale is needed to complete the statistical analysis. It consists of five multidimensional items capturing meaning, personality, fit, work environment, and skill utilization. The items were derived from the literature [6], data from unstructured interviews with in-service firefighters, and the authors' personal observations. This study aims at using confirmatory factor analysis (CFA) to validate that the generated items fit the hypothetical structure.

\section{Methodology}

2.1. Study Design and Respondents. This study aims at evaluating the newly developed SSI and HC scales and determining whether the previous hypothetical structure fits the items via CFA. Data were collected from in-service firefighters in Malaysia between 6/24/2021 and 7/24/2021 via self-administered online questionnaires. The filtered questionnaires were customized depending on respondents' answers pertaining to the type and duration of their service. Respondents stating that they were volunteer/commonservice firefighters or had been in service for 2 years or less were excluded. In this study, data from 6970 out of 8581 respondents were included for further analysis. The total number of respondents exceeded the minimum sample size requirement $(n=977)$. This was calculated using $\mathrm{G} *$ power 3.1.9.2 software [7]. The a priori sample size was calculated with the F-test family with linear multiple regression (fixed model, $R^{2}$ deviation from zero) with the settings as follows: $f^{2}=0.02$ (small effect size), $\alpha=0.05$, number of predictors $=16$, and power set at $80 \%$ (Figure 1).
2.2. Instruments. This study used postexploratory factor analysis of the generated SSI and HC scales. A total of 70 SSI items, excluding two global rating items, were arranged under the dimensions of protection against hazards and welfare. Subdimensions of protection included personal protection suit (PPS, 5 items), workspace (WS, 3 items), equipment used for operation or work (EQUIPMENT, 7 items), documentation related to standard operating procedures or work manual (DOC, 4 items), addressing occupational safety and health issues (OSH, 5 items), workload (WL, 5 items), psychological care (PSYCARE, 6 items), physical fitness (FIT, 6 items), health surveillance (HSURV, 4 items), and supervision (SV, 3 items). Subdimensions of welfare included salary (SALARY, 4 items), special allowance (SP ALLOW, 2 items), compensation for occupational injury or death (COMP, 3 items), career development (CAREER, 4 items), caring (CARE, 5 items), and humanity (HUMANITY, 4 items). All SSI items began with " $I$ am satisfied with ...."

The HC scale consists of five multidimensional items and was used to measure the firefighter's feelings of happiness related to their job in terms of meaning, personality fit, work environment, and skill utilization. A total of three HC items started with "I am happy to work in the Department because..."; the other two items omitted the initial wording because they would have made them too lengthy exceeding 15 words per statement. The respondents were expected to rate their agreement level for SSI and HC using five-point Likert scale ( $1=$ Strongly disagree, $2=$ Disagree, $3=$ Slightly agree, $4=$ Agree, and $5=$ Strongly agree). There was no undecided/natural response, and the respondents were forced to evaluate their own level of agreement rather than "sitting on the fence."

\section{Analysis and Results}

3.1. Data Preparation. The data were screened for blank responses, outliers, and missing values before converting to a .csv file for confirmatory factor analysis (see supplementary material named FRDM SSI HC For PLS SEM.txt). We employed partial least squares structural equation modelling (PLS-SEM) using SmartPLS 3.3.3 [8] as the statistical tool to evaluate the measurement and structural model. PLS-SEM was used because it is able to handle complex models with multidimensional and formative items. It also has the ability to manage nonparametric data, as survey research is not typically distributed normally [9]. We chose hierarchical component modelling, specifically the reflective formative disjoint two-stage approach, because the SSI has two hypothetical dimensions (i.e., protection against hazards and welfare) and 16 subdimensions. The number of items in each subdimension was not similar. In the usual manner, the SSI was regressed on the $\mathrm{HC}$ scale, which consisted of five multidimensional items (Figure 2).

Confirmatory factor analysis: Reflective formative disjoint two-stage approach.

We followed the suggestions of Anderson and Gerbing [10] to test the model developed using a two-step approach. First, the measurement model was tested for validity and to 
TABLE 1: Items of the SSI and HC scale after exploratory factor analysis.

\begin{tabular}{lc}
\hline BIL & ITEM \\
PROTECTION AGAINST HAZARDS
\end{tabular}

A) Personal Protective Suit
A1
$\begin{array}{ll}\text { A2 } & \text { I am satisfied with the material quality of the personal protective suit provided for the operation. } \\ \text { A3 } & \text { I am satisfied with the suitability of personal protective suit for the type of hazards encountered during the operation. } \\ \text { A4 } & \text { I am satisfied with the quantity of personal protective suit supplied to each staff. } \\ \text { A5 } & \text { I am satisfied with the supply of personal protective suit according to the prescribed period/life span. }\end{array}$

B) Facility and Equipment

B1

B2

B3

B4

B5

B6

B7

B8

B9

B10

C)

C1

C2

C3

C4

I am satisfied with the physical security of the office building provided.

I am satisfied with the condition of the office building which is free from the source of the hazard.

I am satisfied with the workspace provided.

I am satisfied with the frequency of building maintenance at work.

I am satisfied with the frequency of maintenance of all types of machinery used for operation.

I am satisfied with the frequency of maintenance of all types of equipment used for the operation.

I am satisfied with the adequacy of the operating equipment provided.

I am satisfied with the adequacy of the equipment to carry out the operational tasks.

I am satisfied with the adequacy of equipment to carry out office tasks (such as computers, printers, and photocopiers).

I am satisfied with the equipment available to meet my job description/function effectively.

ocedure (SOP)/Work Manual

I am satisfied with the standard operating procedure (SOP) provided by the department.

I am satisfied with the Work Manual of all equipment relevant to the current scope of work.

I am satisfied with the training given to all members to understand the standard operating procedure (SOP) documents.

I am satisfied with the training given to all members to understand the Work Manual/standard operating procedure (SOP)

document.

D) Address Occupational Safety and Health issues at the organizational level

D1 I am satisfied with the department's compliance in establishing the Occupational Safety and Health Committee.

D2 I am satisfied with the way incidents and accidents are reported at work through Occupational Safety and Health Committee.

D3 I am satisfied with the implementation of safety-related training for all staff.

D4 I am satisfied with the frequency of fire drill at work.

D5 I am satisfied with my own ability to deal with emergency situations at work.

E) Workload

E1

E2

E3

$\mathrm{E} 4$

E5

F) Psychological/emotional care

F1

F2

F3

F4

F5

F6

G) Physical fitness

G1

G2

G3

G4

G5

G6

I am satisfied with the distribution of workload given to individuals.

I am satisfied with the workload distribution after taking into account the norms of group workability.

I am satisfied with the setting of norms by the department for each operation assigned.

I am satisfied with the fairness of the workload for both male and female staff.

I am satisfied with the adequacy of the training provided to deal with the workload.

I am satisfied with my psychological care management while carrying out assigned tasks.

I am satisfied with the management of psychological support by the department to staff in the wake of traumatic incidents.

I am satisfied with the psychological support services provided to me in the wake of the traumatic incident.

I am satisfied with my supervisor who is always ready to provide psychological support to me in the wake of a traumatic incident.

I am satisfied with the appropriateness of the working hours to take care of my psychology.

I am satisfied with the way my supervisor handles the concerns I express.

I am satisfied with the setting of physical fitness standards that must be achieved by all.

I am satisfied with my current body mass index.

I am satisfied with the implementation of the Individual Physical Proficiency Test (IPPT).

I am satisfied with the Individual Physical Proficiency Test (IPPT) measurement method of individuals.

I am satisfied with setting the ideal level of physical fitness with the tasks performed.

I am satisfied with the frequency of implementation of physical fitness exercises at least once a week.

H) Health monitoring

$\mathrm{H} 1$

$\mathrm{H} 2$

$\mathrm{H} 3$

$\mathrm{H} 4$
I am satisfied with the way health monitoring is managed by the department.

I am satisfied with the frequency of health check-ups at least once a year.

I am satisfied with the implementation of a health examination after staff is exposed to a health-hazardous operation.

I am satisfied with the department's collaboration with health organizations to monitor the health of staff.

\section{I) Supervision in the workplace}

I1

I am satisfied with the professionalism of my teammates at work.

I2 
TABLE 1: Continued.

\begin{tabular}{|c|c|}
\hline BIL & $\begin{array}{c}\text { ITEM } \\
\text { PROTECTION AGAINST HAZARDS }\end{array}$ \\
\hline $\mathrm{I} 3$ & I am satisfied with my supervisor who creates a spirit of teamwork. \\
\hline PG & Overall, I am satisfied with the element of protection from occupational hazards provided by the Department to staff. \\
\hline \multicolumn{2}{|c|}{ WELFARE } \\
\hline KA1 & I am satisfied with the special unit allowance rate given by the Department. \\
\hline KA2 & I am satisfied with the rate of Fire Incentive Payment allowance given by the Department. \\
\hline KA3 & I am satisfied that the rate of allowance for special forces members is commensurate with the level of danger faced. \\
\hline KA6 & I am satisfied with the current salary I earn with my workload. \\
\hline \multicolumn{2}{|c|}{ 2KA) Special allowance } \\
\hline 2KA4 & I am satisfied $\mathrm{i}$ \\
\hline 2KA5 & rescue technical expertise units (such as MUST, STORM, HRTR etc.). \\
\hline \multicolumn{2}{|c|}{ KB) Compensation of Rescuers (Personal and Family) } \\
\hline KB1 & I am satisfied with the management of the \\
\hline KB2 & I am satisfied with the adequacy of the amount of compensation obtained by a disabled staff while on duty. \\
\hline KB3 & $\begin{array}{c}\text { I am satisfied with the adequacy of the amount of compensation obtained by the families of staff who lost their lives while on } \\
\text { duty. }\end{array}$ \\
\hline
\end{tabular}

\section{KC) Career development}

KC1 I am satisfied with the willingness of the department to give permission to staff who wish to further their studies (Diploma, Degree, Master or Phd).

KC2 I am satisfied if the Department provides promotion opportunities to officers and staff who have furthered their studies in the academic field.

KC3 I am satisfied with the encouragement from the Department to officers and staff to enhance their personal development in any professional body (e.g., Lembaga Arkitek Malaysia and Board Engineering Malaysia)

KC4 I am satisfied with the inspiration from the Department to staff to attend relevant technical seminars.

KP) Care

KD1 I am satisfied with the gym/indoor leisure facilities provided by the Department to ensure the physical fitness of the staff in a $(K P 1)$

KE1 (KP2) satisfactory level.

KE2 (KP3) I am satisfied with the Department's concern taking over the routine task of managing the schooling of the children of officers and staff when outstation (e.g., providing transportation to school).

KE3 (KP4) I am satisfied with the flexibility of the Department to officers and staff to manage the schooling of children during nonemergency working hours.

KE4 (KP5) I am satisfied with the decision of the Department to order the placement of officers and staff after considering the factors of the location of the family's residence and the couple's employment.

KE) Humanity

KE5

(KH1)

KE6

(KH2)

KE7

(KH3)

KE9

(KH4)

WG
I am satisfied with the current workplace distance from the residential location.

I am satisfied with the permission given by the Department to officers and staff to do work outside of duty hours (such as lawn mowing work, driving e-hailing, associations, teaching etc.).

I am satisfied with the Department allowing me to take sick leave that has been certified by a recognized medical practitioner.

I am satisfied with the permission to perform light duty duties to officers and staff who have health problems.

Overall, I am satisfied with the welfare element provided by the Department to the members.

\begin{tabular}{|c|c|}
\hline Happiness at work & \\
\hline S1 & I am happy to work in the Department because this job gives meaning and purpose. \\
\hline S2 & I am happy to work in the Department because the given tasks suit my personality. \\
\hline S3 & I am happy to work in the Department because I feel proud to be a part of its staff. \\
\hline S4 & The Department has created a work environment where I can deliver the best possible service. \\
\hline S5 & I can give additional efforts and contributions to achieve the Department's mission. \\
\hline
\end{tabular}

Note. PG, WG, SSG, and SG are global subdimensions. Italics indicate a new item label postexploratory factor analysis. KB4, KC5, KD2, KD3, and KE8 were excluded after the exploratory factor analysis using Promax rotation with Kaiser normalization. 
Q G*Power 3.1.9.2

File Edit View Tests Calculator Help

\section{Central and noncentral distributions Protocol of power analyses}

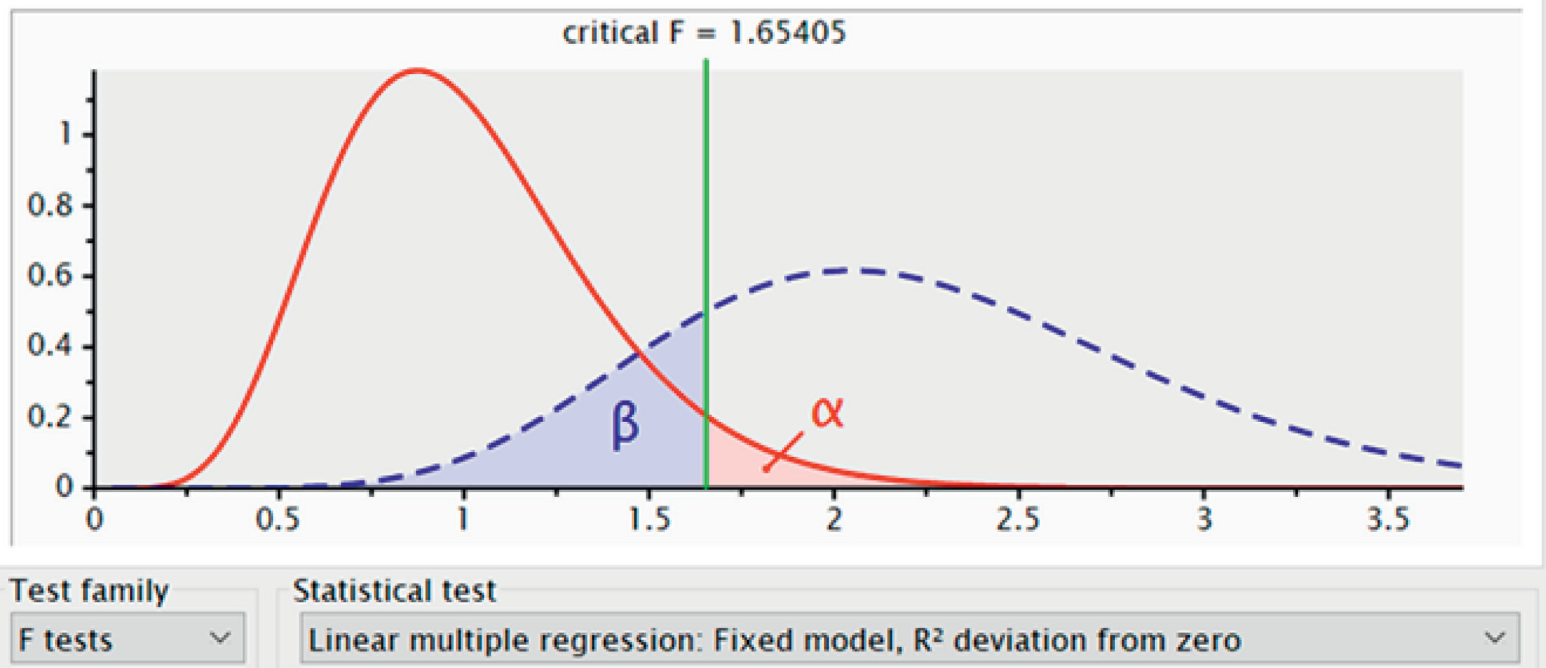

Type of power analysis

A priori: Compute required sample size - given $\alpha$, power, and effect size

\begin{tabular}{|c|c|c|}
\hline \multicolumn{3}{|c|}{ Input Parameters } \\
\hline Determine $=>$ & Effect size $f^{2}$ & $\begin{array}{l}0.02 \\
0.02\end{array}$ \\
\hline & $\alpha$ err prob & 0.05 \\
\hline \multicolumn{2}{|c|}{ Power ( 1 - $\beta$ err prob) } & 0.80 \\
\hline \multicolumn{2}{|c|}{ Number of predictors } & 16 \\
\hline
\end{tabular}

Output Parameters

Noncentrality parameter $\lambda$

\begin{tabular}{r|r} 
Critical F & 1.6540506 \\
\cline { 2 - 2 } Numerator df & 16 \\
\cline { 2 - 2 } Denominator df & 960 \\
\cline { 2 - 2 } Total sample size & 977 \\
\cline { 2 - 2 } Actual power & 0.8002080
\end{tabular}

Figure 1: Sample size calculation using $G *$ power 3.1.9.2 software.

determine the reliability of the instruments. Next, a structural model was used to test the validity, collinearity, significance, and relevance of the formative subdimensions using the guidelines given by Hair et al. [11] and Ramayah et al. [12].

\subsection{Measurement Model Analysis}

Step 1. Drawing specified hypothetical subdimensions.

In the SmartPLS workspace, a model, as shown in Figure 2, was drawn. All 16 hypothetical subdimensions were regressed to the $\mathrm{HC}$ endogenous construct. We then used Calculate $>$ PLS Algorithm to obtain factor loading and average variance extracted (AVE) to assess convergent validity, composite reliability (CR) to assess each subdimension's internal reliability, heterotrait-monotrait ratio of correlation (HTMT) to assess discriminant validity, and latent variable for assessing the structural model of the reflective formative disjoint two-stage analysis at a later stage. We copied and pasted each subdimension's latent variables in the original file and saved it as a new .csv file for normality testing. In the file, we added the column 


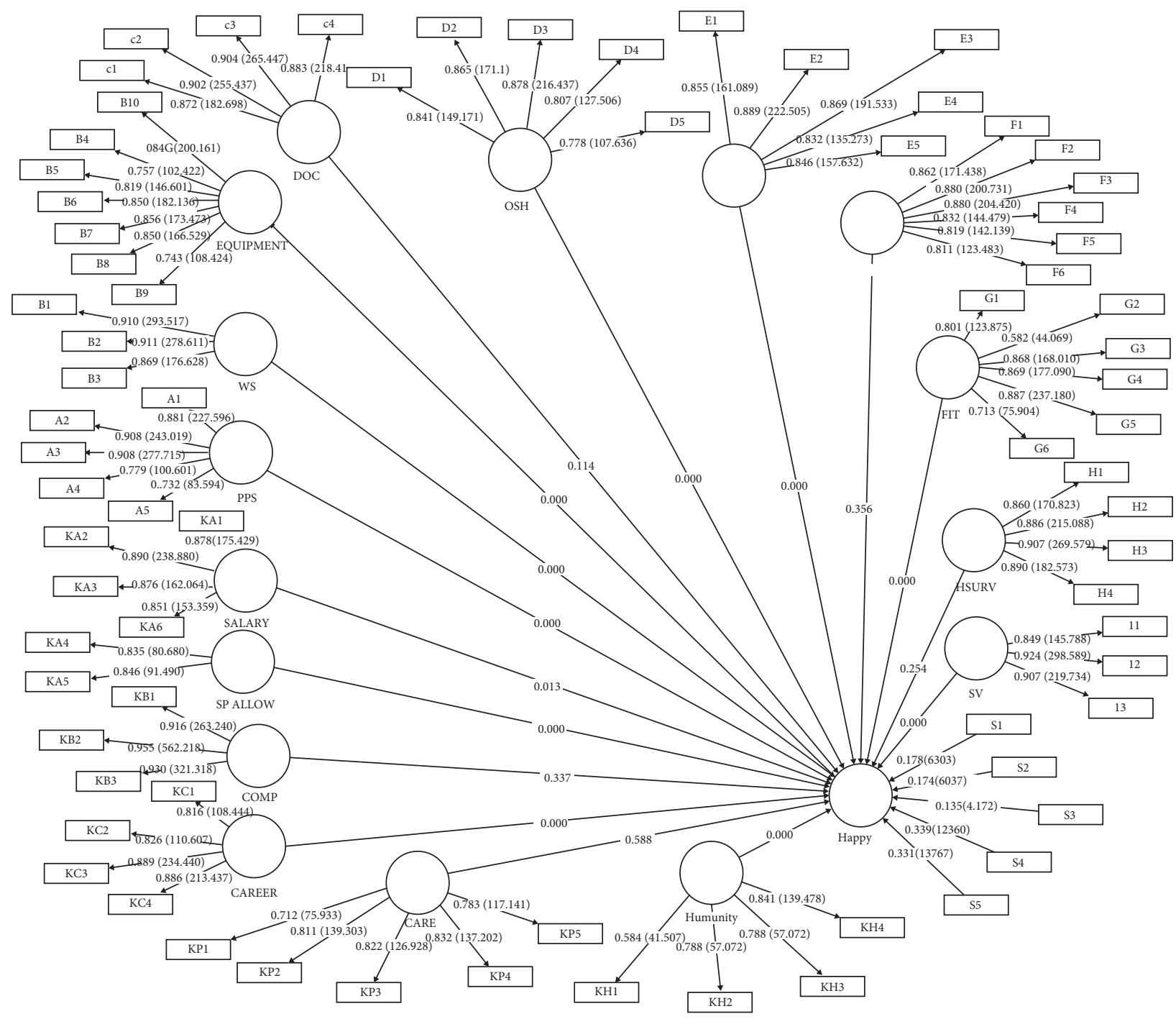

FIgURe 2: Measurement model.

RANDOM with the formula RAND() followed by "Enter" and "Tab," double-clicked the plus sign, and saved the file for assessing common method bias using full collinearity testing (see supplementary material named FRDM SSI HC LV.txt).

\section{Step 2. Checking normality}

Using WebPower's statistical power analysis, we calculated Mardia's multivariate skewness and kurtosis. The values of skewness and kurtosis should range from -1 to +1 and -20 to +20 , respectively. These data were non-normally distributed. Mardia's multivariate skewness showed $b=23.414, z=27199.707$, and $p<0.001$, while Mardia's multivariate kurtosis showed $b=461.647, z=302.025$, and $p<0.001$.

Step 3. Checking for common method bias

Since the data were collected from a single source, we first tested for common method bias by following the suggestions of Kock and Lynn [13], namely, to test full collinearity. In this method, all 17 constructs were regressed on a RANDOM variable using IBM SPSS version 26. There is no bias from the single source data if the variance inflation factor (VIF) $\leq 5$ [14]. The analysis yielded a VIF consistently less than 5 (Table 2); thus, single source bias is not a serious issue with our data.

Step 4. Measurement model assessment

On the one hand, all 16 subdimensions of the SSI are reflective; on the other hand, the $\mathrm{HC}$ scale is a formative model (Figure 2). For the reflective measurement model, we assessed the loading, AVE, and CR. The value of the loading should be $\geq 0.5$, the AVE should be $\geq 0.5$, and the CR should be $\geq 0.7$. As shown in Table 3 , the AVEs are all higher than 0.5 and the CRs are all higher than 0.7. All loadings are higher than 0.708 , indicating that a latent variable is able to explain at least $50 \%$ of the subdimension's variance [11]. No item was deleted. For the formative measurement model, we assessed the bootstrapped outer weight significance and outer VIF. All bootstrapped outer weights are significant at a 
TABLE 2: Full collinearity testing.

\begin{tabular}{lc}
\hline Constructs & VIF \\
\hline CARE & 2.309 \\
CAREER & 1.834 \\
COMP & 2.257 \\
DOC & 3.467 \\
EQUIPMENT & 3.083 \\
FIT & 2.159 \\
HSURV & 2.033 \\
HUMANITY & 1.830 \\
OSH & 3.354 \\
PPS & 1.857 \\
PSYCARE & 3.747 \\
SALARY & 2.193 \\
SP ALLOW & 1.337 \\
SV & 1.955 \\
WL & 3.265 \\
WS & 2.156 \\
HAPPY & 1.916 \\
\hline
\end{tabular}

Note. Dependent variable $=$ random value; $\mathrm{CARE}=$ caring; CAREER= career development; $\mathrm{COMP}=$ compensation for occupational injury or death; $\mathrm{DOC}=$ documentation related to standard operating procedure or manual; EQUIPMENT = equipment used for operation or work; FIT = physical fitness; HSURV = health surveillance; HUMANITY = humanity; $\mathrm{OSH}=$ addressing occupational safety and health; $\mathrm{PPS}=$ personal protective suit; $\quad$ PSYCARE $=$ psychological care; $S A L A R Y=$ salary; SP ALLOW= special allowance; $\mathrm{SV}=$ supervision; $\mathrm{WL}=$ workload; $\quad$ WORKSPACE $=$ workspace; HAPPY $=$ HC.

TABLE 3: Measurement model for reflective dimension.

\begin{tabular}{|c|c|c|c|c|}
\hline First order & Items & Loadings & CR & AVE \\
\hline \multirow{5}{*}{ PPS } & A1 & 0.881 & \multirow{5}{*}{0.925} & \multirow{5}{*}{0.713} \\
\hline & $\mathrm{A} 2$ & 0.908 & & \\
\hline & $\mathrm{A} 3$ & 0.908 & & \\
\hline & A4 & 0.779 & & \\
\hline & A5 & 0.732 & & \\
\hline \multirow{3}{*}{ WS } & B1 & 0.910 & \multirow{4}{*}{0.925} & \multirow{3}{*}{0.805} \\
\hline & B2 & 0.911 & & \\
\hline & B3 & 0.869 & & \\
\hline \multirow{7}{*}{ EQUIPMENT } & B4 & 0.757 & & \multirow{7}{*}{0.670} \\
\hline & B5 & 0.819 & \multirow{6}{*}{0.934} & \\
\hline & B6 & 0.850 & & \\
\hline & B7 & 0.856 & & \\
\hline & B8 & 0.850 & & \\
\hline & B9 & 0.743 & & \\
\hline & B10 & 0.846 & & \\
\hline \multirow{4}{*}{ DOC } & $\mathrm{C} 1$ & 0.872 & \multirow{4}{*}{0.939} & \multirow{4}{*}{0.793} \\
\hline & $\mathrm{C} 2$ & 0.902 & & \\
\hline & C3 & 0.904 & & \\
\hline & $\mathrm{C} 4$ & 0.883 & & \\
\hline \multirow{5}{*}{ OSH } & D1 & 0.841 & \multirow{5}{*}{0.92} & \multirow{5}{*}{0.697} \\
\hline & D2 & 0.865 & & \\
\hline & D3 & 0.878 & & \\
\hline & D4 & 0.807 & & \\
\hline & D5 & 0.778 & & \\
\hline \multirow{5}{*}{ WL } & E1 & 0.855 & \multirow{5}{*}{0.933} & \multirow{5}{*}{0.737} \\
\hline & E2 & 0.889 & & \\
\hline & E3 & 0.869 & & \\
\hline & $\mathrm{E} 4$ & 0.832 & & \\
\hline & E5 & 0.846 & & \\
\hline
\end{tabular}

TABle 3: Continued.

\begin{tabular}{|c|c|c|c|c|}
\hline First order & Items & Loadings & CR & $\overline{A V E}$ \\
\hline \multirow{6}{*}{ PSYCARE } & $\mathrm{F} 1$ & 0.862 & \multirow{6}{*}{0.939} & \multirow{6}{*}{0.719} \\
\hline & $\mathrm{F} 2$ & 0.880 & & \\
\hline & F3 & 0.880 & & \\
\hline & $\mathrm{F} 4$ & 0.832 & & \\
\hline & F5 & 0.819 & & \\
\hline & F6 & 0.811 & & \\
\hline \multirow{5}{*}{ FITNESS } & G1 & 0.801 & \multirow{5}{*}{0.91} & \multirow{5}{*}{0.631} \\
\hline & G2 & 0.582 & & \\
\hline & G3 & 0.868 & & \\
\hline & G4 & 0.869 & & \\
\hline & G5 & 0.887 & & \\
\hline \multirow{4}{*}{ HSURV } & $\mathrm{H} 1$ & 0.860 & \multirow{4}{*}{0.936} & \multirow{4}{*}{0.785} \\
\hline & $\mathrm{H} 2$ & 0.886 & & \\
\hline & $\mathrm{H} 3$ & 0.907 & & \\
\hline & $\mathrm{H} 4$ & 0.890 & & \\
\hline \multirow{3}{*}{ SV } & I1 & 0.849 & \multirow{4}{*}{0.923} & \multirow{3}{*}{0.799} \\
\hline & $\mathrm{I} 2$ & 0.924 & & \\
\hline & I3 & 0.907 & & \\
\hline \multirow{4}{*}{ SALARY } & KA1 & 0.878 & & \multirow{4}{*}{0.764} \\
\hline & KA2 & 0.890 & \multirow{3}{*}{0.928} & \\
\hline & KA3 & 0.876 & & \\
\hline & KA6 & 0.851 & & \\
\hline \multirow{2}{*}{ SP ALLOW } & KA4 & 0.835 & \multirow{3}{*}{0.828} & \multirow{3}{*}{0.706} \\
\hline & KA5 & 0.846 & & \\
\hline \multirow{3}{*}{ COMP } & KB1 & 0.916 & & \\
\hline & KB2 & 0.955 & \multirow[t]{2}{*}{0.953} & \multirow[t]{2}{*}{0.872} \\
\hline & KB3 & 0.930 & & \\
\hline \multirow{4}{*}{ CAREER } & $\mathrm{KC} 1$ & 0.816 & \multirow{4}{*}{0.917} & \multirow{3}{*}{0.736} \\
\hline & $\mathrm{KC} 2$ & 0.826 & & \\
\hline & KC3 & 0.899 & & \\
\hline & $\mathrm{KC4}$ & 0.886 & & \\
\hline \multirow{5}{*}{ CARE } & KP1 & 0.712 & \multirow{5}{*}{0.894} & \\
\hline & KP2 & 0.811 & & \\
\hline & KP3 & 0.822 & & 0.629 \\
\hline & KP4 & 0.832 & & \\
\hline & KP5 & 0.783 & & \\
\hline & $\mathrm{KH} 1$ & 0.584 & & \\
\hline HUMANITY & $\mathrm{KH} 2$ & 0.788 & & \\
\hline & KH3 & 0.869 & 0.858 & 0.606 \\
\hline & KH4 & 0.841 & & \\
\hline $\begin{array}{l}\text { Note. PPS = per } \\
\text { PMENT = equipm } \\
\text { related standard } \\
\text { cupational safety } \\
\text { care; FIT = physic } \\
\text { SALARY = salary; } \\
\text { velopment; CON } \\
\text { CARE = caring; H }\end{array}$ & $\begin{array}{l}\text { prote } \\
\text { used for } \\
\text { ating pro } \\
\text { health; } \\
\text { hess; HSU } \\
\text { ALLOW } \\
\text { compensa } \\
\text { ANITY = }\end{array}$ & $\begin{aligned} & \text { suit; } \\
& \text { ation or wor } \\
& \text { re or manu } \\
&=\text { workload; } \\
&=\text { health surv } \\
& \text { cial allowan } \\
& \text { for occup } \\
& \text { anity. }\end{aligned}$ & $\begin{array}{l}\text { worksp } \\
\mathrm{OC}=\mathrm{d} \\
\mathrm{SH}=\mathrm{a} \\
\mathrm{ARE}= \\
\mathrm{ce} \text { SV } \\
\text { AREEI } \\
\text { al inju }\end{array}$ & $\begin{array}{l}\text { EQUI- } \\
\text { entation } \\
\text { ing oc- } \\
\text { ological } \\
\text { ervision; } \\
\text { reer de- } \\
\text { death; }\end{array}$ \\
\hline
\end{tabular}

critical value of more than 2.58 , and the subdimensions are distinct (Table 4). We then assessed discriminant validity using the HTMT criterion suggested by Henseler et al. [15] and updated by Franke and Sarstedt [16]. The HTMT values should be $\leq 0.90$. As shown in Table 5, the HTMT values of each construct are $\leq 0.90$. Hence, we can conclude that the respondents understood that the 16 reflective constructs were distinct. The measurement model is both valid and reliable.

Step 5. Structural model assessment

For the structural model, we assessed the convergent validity by redundancy analysis. In assessing convergent 
TABLE 4: Measurement model for the formative dimension.

\begin{tabular}{lcccc}
\hline First order & Items & Weight & $t$-value & VIF \\
\hline \multirow{4}{*}{ HAPPINESS } & S1 & 0.178 & 6.303 & 3.277 \\
& S2 & 0.174 & 6.037 & 3.098 \\
& S3 & 0.135 & 4.172 & 2.962 \\
& S4 & 0.339 & 12.360 & 2.334 \\
& S5 & 0.331 & 13.767 & 2.259 \\
\hline
\end{tabular}

validity, a global indicator was designed for each formative construct. We used three global rating items, namely, for the construct of protection against hazard at work (PG), welfare (WG), and HC (SG), respectively (Figure 3 ). The redundancy results range between almost 0.7 and more than 0.8 (Figure 3). Therefore, the formative subdimensions of the construct do contribute to its intended content at a sufficient level of convergent validity.

A total of 16 latent variables from Step 1 was used to draw the reflective formative disjoint two-stage approach (Figure 4). The significance and relevance of formative subdimensions were assessed by looking at the bootstrapping values of the outer weights. Based on the results shown in Table 6, all subdimensions in the formative construct satisfy the VIF values of less than 5 [17]. It can be concluded that collinearity is not an issue for the estimation of the PLS path model. The significance and relevance of formative subdimensions were examined. The results show that all formative subdimensions are significant except for health surveillance and psychological care. Prior literature provides evidence for the relevance of these subdimensions for capturing the attributes of protection against hazards at work $[18,19]$. Hence, these subdimensions are retained in the formative protection construct even though their outer weights are not significant.

\section{Step 6. SSI and HC path model assessment}

Prior to testing the SSI and HC path model, the issue of lateral collinearity was examined to reveal the robust cause and effect between SSI and HC. In this model, the enhancement of the hypothetical SSI leads to happiness among firefighters. A stricter VIF value of 3.3 or up to 5 was employed to indicate the absence of potential collinearity issue [20]. Since the data were not normal, we followed the bootstrap procedure, using 7000 subsamples to avoid inflation or deflation of the standard errors due to non-normality issues. We reported a bias-corrected confidence interval for path coefficients $(\beta)$. We considered a $\beta$ of 0.21 and above as a significant parameter [21]. Later, we assessed the coefficients of determination $\left(R^{2}\right)$, effect size $\left(f^{2}\right)$, and predictive relevance $\left(Q^{2}\right)$.

$R^{2}$ is a measure of the model's predictive accuracy (i.e., the combined effect of exogenous variables on endogenous variables). $R^{2}$ represents the amount of variance in the HC scale explained by all formative subdimensions in protection against hazards and welfare and the exogenous constructs linked to it. Past and contemporary scholars provide a different acceptable $R^{2}$ based on the area of research. Cohen [22]; a Professor of Psychology, suggested $0.26,0.13$, and 0.02 to describe substantial, moderate, and weak levels of predictive accuracy, respectively. Almost three decades later, Hair et al. [17] suggested 0.75, 0.50, and 0.25 to describe substantial, moderate, and weak levels of predictive accuracy, respectively. Interestingly, Falk and Miller [23] suggested the lowest acceptable $R^{2}$ value, 0.10 or higher, to explain the variance of a particular endogenous construct.

To ensure complete reporting, the effect size of the protection and welfare constructs were further evaluated using Cohen $f^{2}$. According to Cohen [24], $f^{2}$ values of 0.35 , 0.15 , and 0.02 are considered large, medium, and small effect sizes, respectively. Lastly, the $Q^{2}$ via the blindfolding procedure was calculated, which removes data from the dataset based on the predetermined distance value, called $D$. The $D$ value can be any number from 5 to 12 . In this procedure, a $D$ value of 7 was chosen so that the 6970 observations in the dataset were divided by 7 , giving 995.7, which is not an integer. Chin [25] concluded that a $Q^{2}$ larger than 0 indicates that exogenous constructs have predictive relevance for an endogenous construct.

Based on the assessment of the path coefficient, shown in Table 7, both relationships were found to have a $t$-value $\geq 2.33$, which is significant at a 0.01 level of significance. The predictors of protection against hazards at work $(\beta=0.370$, $p<0.001)$ and welfare $(\beta=0.375, p<0.001)$ are positively related to happiness, explaining $46.6 \%$ of the variance in happiness at work. The $R^{2}$ value of 0.466 is above the 0.26 value suggested by Cohen [22], indicating a substantial model. The predictors have small-to-medium effect sizes (the Cohen $f^{2}$ is near 0.15) and relevance in predicting happiness $\left(Q^{2}=0.339\right)$.

\section{Discussion}

This study aims at demonstrating the validation process of SSI and HC as a final phase of a systematic scale development and scale validation. We chose to perform an upto-date empirical PLS-SEM analysis using hierarchical component modelling, namely, the reflective formative disjoint two-stage approach. This is because the SSI is complex, with a total of 70 items that are not uniformly distributed in their respective subdimensions. A total of 16 solidified SSI subdimensions unevenly distributed under two dimensions were examined. These dimensions included protection against hazards at work and welfare. Out of the 16 SSI subdimensions, only two did not show significant relevance to assessing firefighter's satisfaction (health surveillance and psychological care). However, one cannot assume that these subdimensions have no impact on one's assessment of personal job satisfaction pertaining to the content and context of the said job, especially among firefighters.

Health surveillance, especially in regard to the respiratory system, is vital to firefighters, who are constantly exposed to smoke and various by-products of combustion, including polycyclic aromatic hydrocarbons, volatile organic compounds, di-(2-ethylhexyl) phthalate, and polybrominated diphenyl ethers, which are far more toxic than the contaminates released from fires decades ago [26]. 


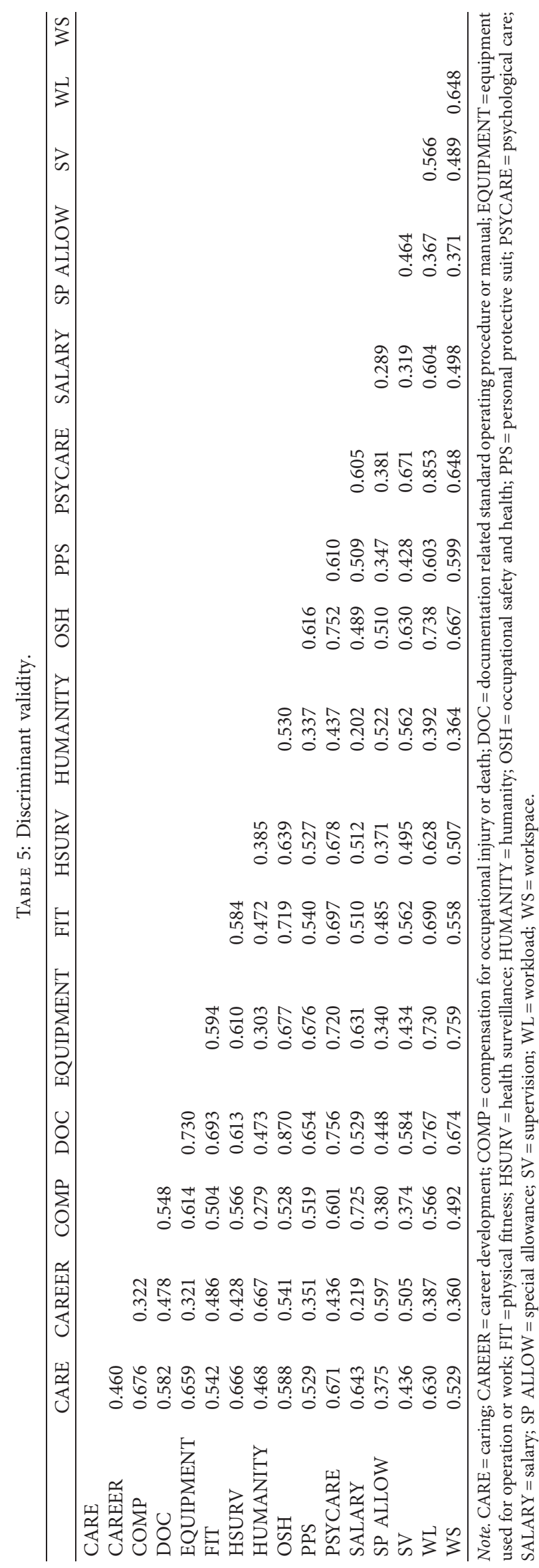




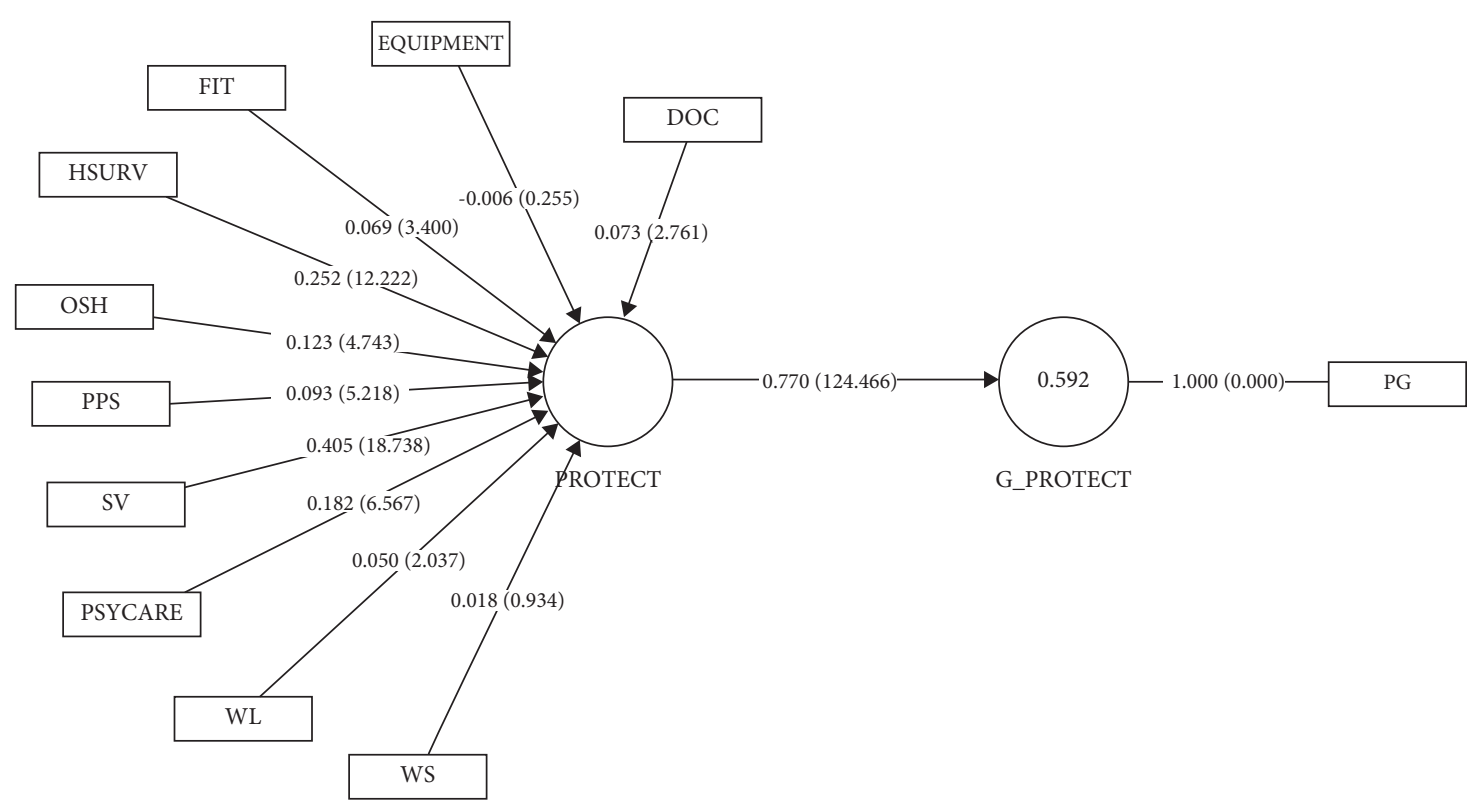

(a)

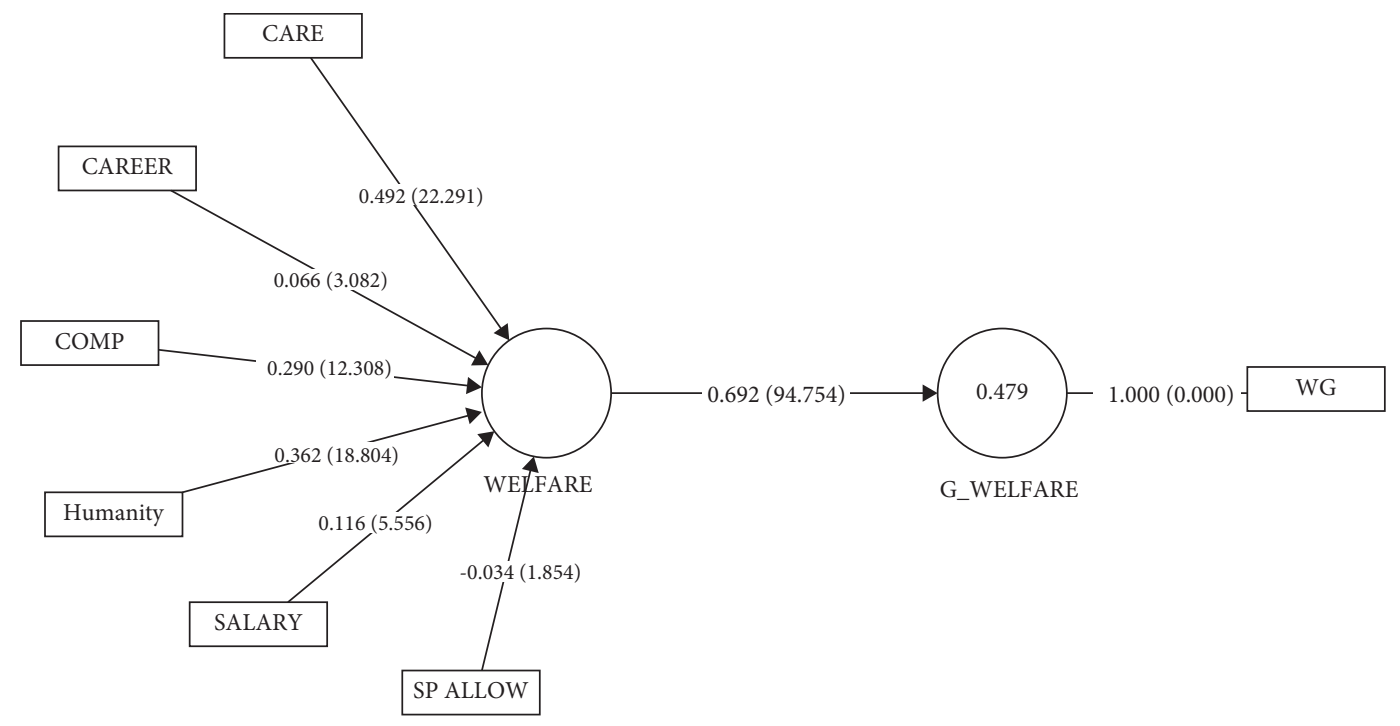

(b)

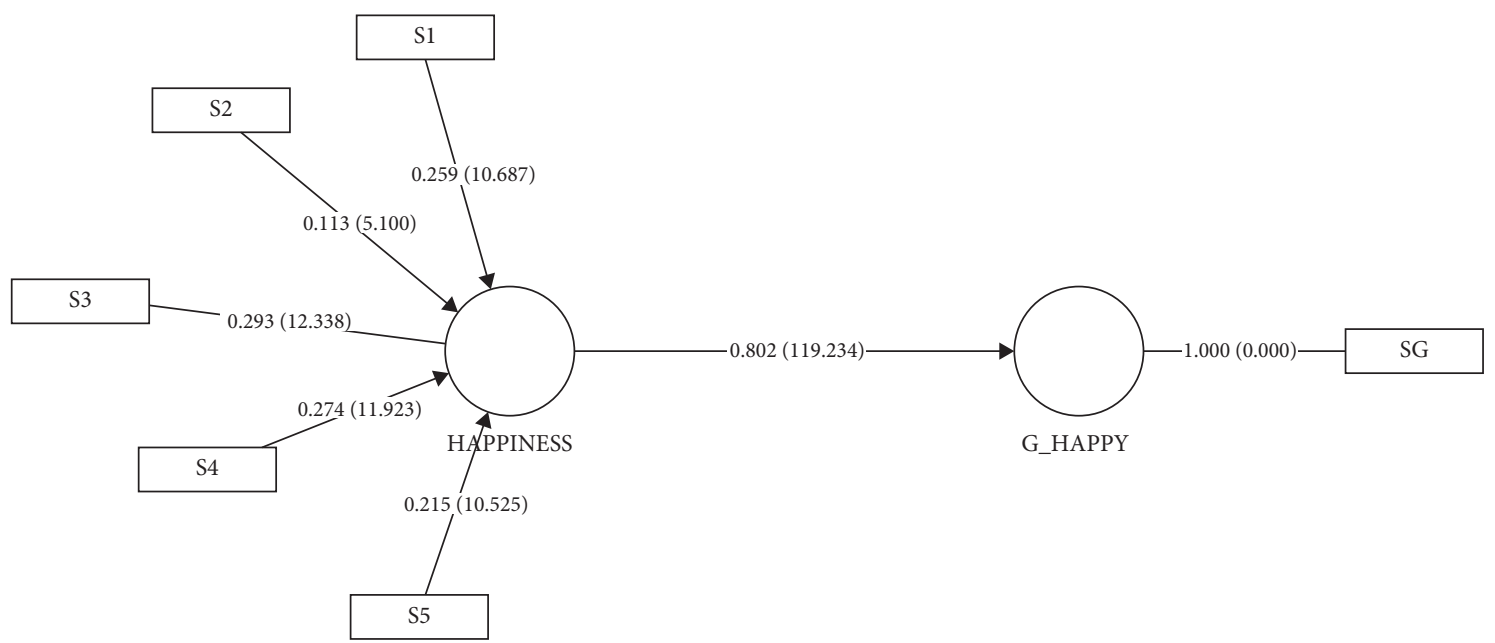

(c)

FIGURE 3: Convergent validity by redundancy analysis. 


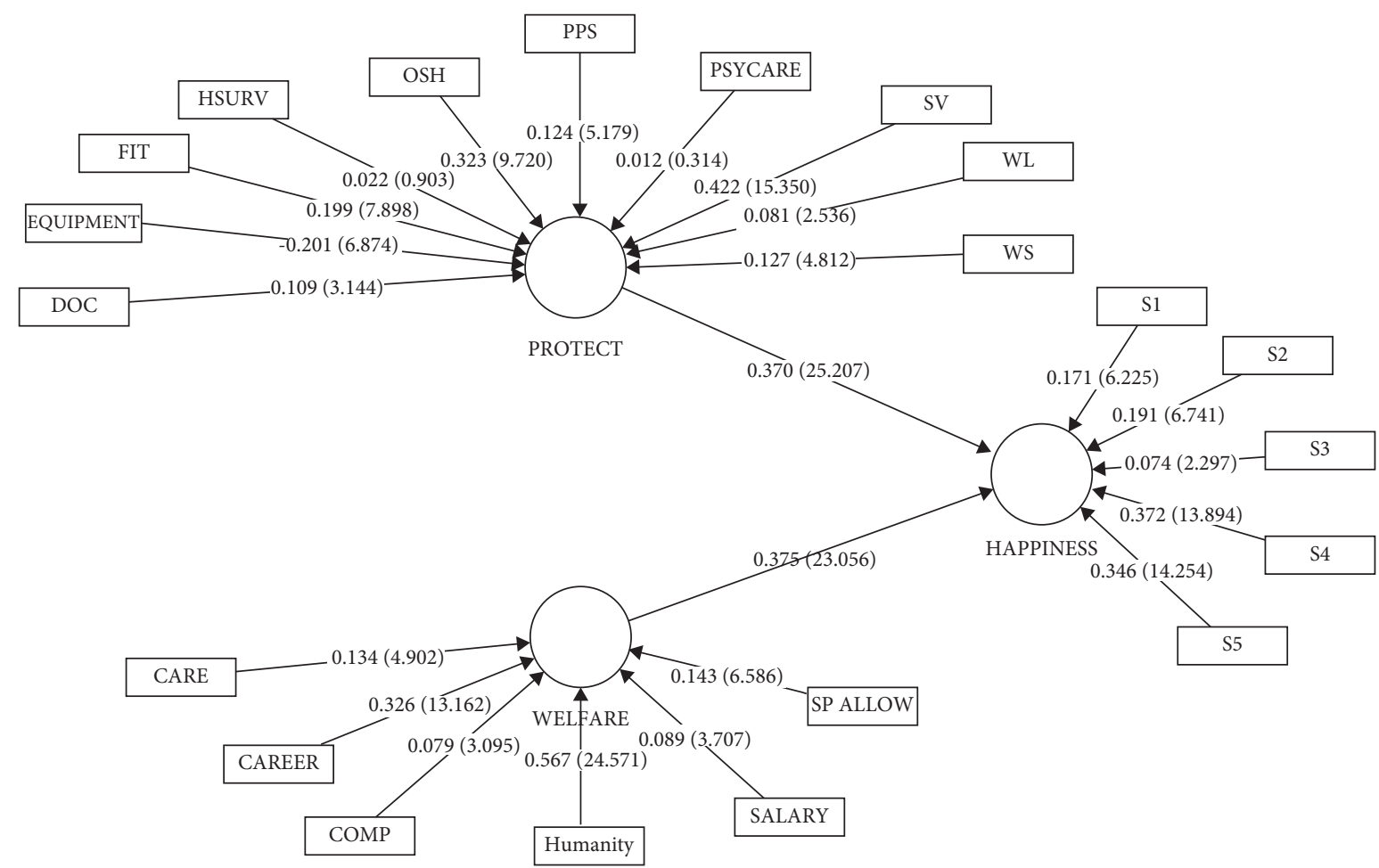

FIGURE 4: Reflective formative disjoint two-stage structural model.

TABLE 6: Reflective formative disjoint two-stage structural model.

\begin{tabular}{|c|c|c|c|}
\hline & Weight & $t$-value & VIF \\
\hline \multicolumn{4}{|l|}{ PROTECTION } \\
\hline WL & 0.081 & 2.536 & 3.204 \\
\hline WS & 0.127 & 4.812 & 2.144 \\
\hline SV & 0.422 & 15.350 & 1.745 \\
\hline DOC & 0.109 & 3.144 & 3.443 \\
\hline EQUIPMENT & -0.201 & 6.874 & 2.846 \\
\hline FIT & 0.199 & 7.898 & 2.072 \\
\hline HSURV & 0.022 & 0.903 & 1.859 \\
\hline $\mathrm{OSH}$ & 0.323 & 9.720 & 3.216 \\
\hline PPS & 0.124 & 5.179 & 1.827 \\
\hline PSYCARE & 0.012 & 0.314 & 3.612 \\
\hline \multicolumn{4}{|l|}{$\overline{\text { WELFARE }}$} \\
\hline CARE & 0.134 & 4.902 & 1.987 \\
\hline CAREER & 0.326 & 13.162 & 1.685 \\
\hline COMP & 0.079 & 3.095 & 2.135 \\
\hline SALARY & 0.089 & 3.707 & 1.960 \\
\hline SP ALLOW & 0.143 & 6.586 & 1.291 \\
\hline HUMANITY & 0.567 & 24.571 & 1.555 \\
\hline \multicolumn{4}{|l|}{ HAPPINESS } \\
\hline S1 & 0.171 & 6.225 & 3.277 \\
\hline S2 & 0.191 & 6.741 & 3.098 \\
\hline S3 & 0.074 & 2.297 & 2.962 \\
\hline S4 & 0.372 & 13.894 & 2.334 \\
\hline S5 & 0.346 & 14.254 & 2.259 \\
\hline
\end{tabular}

Note. PPS = personal protective suit; WS = workspace; EQUIPMENT = equipment used for operation or work; DOC = documentation related standard operating procedure or manual; OSH $=$ addressing occupational safety and health; $\mathrm{WL}=$ workload; PSYCARE $=$ psychological care; FIT $=$ physical fitness; HSURV = health surveillance; $S V=$ supervision; SALARY = salary; SP ALLOW = special allowance; CAREER = career development; COMP = compensation for occupational injury or death; CARE = caring; HUMANITY = humanity. 
TABLE 7: SSI and HC path model assessment.

\begin{tabular}{lcccccccc}
\hline & $\beta$ & BCI LL & BCI UL & SE & $t$-value & $p$ & $f^{2}$ & VIF \\
\hline PROTECT- > HAPPINESS & 0.370 & 0.344 & 0.392 & 0.015 & 24.893 & $<0.001$ & 0.137 & 1.871 \\
WELFARE- $>$ HAPPINESS & 0.375 & 0.348 & 0.402 & 0.016 & 22.947 & $<0.001$ & 0.140 & 1.871 \\
\hline
\end{tabular}

$R^{2}=0.466\left(Q^{2}=0.339\right)$.

While the use of self-contained breathing apparatus during fire suppression operations has increased, the breathing apparatus is not consistently used prior to or during overhaul activities because of habitual practices or mismatching demands and supplies, which leads to adverse health effects among firefighters. Therefore, there is caused to be concerned about the respiratory health of firefighters. Although Malaysia has never experienced any deadliest fire before [27], Malaysia had an average rate of fire incidents of around 1025 fires per million inhabitants per year from 2006 to 2014 [28]. While a residential fire may take 30 minutes to put out, a bushfire may take up 14,400 minutes or more. This is considered a significant exposure to the firefighter's respiratory system.

In some states, the Fire and Rescue Department routinely performs medical examinations to assess general physical health and includes a routine panel of blood tests for chronic diseases, vision and hearing tests, electrocardiograms, and a lung-function test [29]. Unfortunately, these examinations are not adjusted based on what firefighters' respiratory systems have been exposed to in an operation period. Matching biomarkers of exposure (e.g., 1-hydroxypyrene or protein adducts) or biomarkers of effect (e.g., eosinophils levels) to a specific exposure should be regularly tested. Furthermore, no pattern analysis was performed to determine whether there is a trend in lung function over time. Firefighters may be deemed "not fit for duty" after years of service, which may lead to a reduction of functional crews. Mathias et al. [26] found that firefighters had decreased lung function at rates two to four times greater than expected over 5 years. In addition to a history of smoking, exposure to smoke and various combustion by-products over years of service may have increased the risk for interstitial lung disease and autoimmunity in firefighters [30]. This may cause premature death. Therefore, the health surveillance subdimension of the SSI should be maintained.

The environment of firefighters is physically and psychologically demanding. Some often think of the mind and body as being separate, but mental and physical health are closely interrelated. In a firefighter's world, responding to a dirty, dangerous, demeaning, and chaotic environment is rarely discussed. Therefore, it is not thought to be an issue; in fact, it is a taboo topic. This is because firefighters are real-life heroes. They run toward danger. They are one of the first officials to reach the scene in times of crisis. They know that there is a chance that specific tactics might not go as planned. Nevertheless, they are motivated to do more, to go beyond their pay rate. It is likely that in these moments, firefighters might have a glimpse of an undesirable memory that needs to be dealt with professionally. Being heroes, they are unlikely to vent their stress and trauma with those they are close to, even their wives. If they are not being asked, no one knows what they are going through internally [31]. A possible mechanism to execute such a delicate enquiry is the Employee Assistance Program (EAP), which can prevent late detection of psychological issues when someone has attempted suicide.

The EAP aims at performing crisis interventions and at offering education on stress management and other shortterm assistance with various life challenges [32]. This is necessary because every working adult may experience workfamily and work-life conflicts that lead to various health consequences, such as burnout [33], and firefighters are no exception [34]. It is important to help affected firefighters become resilient in every possible opportunity. Although the EAP has been repeatedly proven to be an essential element in nurturing resilience, especially within critical uniformed organizations, the EAP is an "extraterrestrial program" in Malaysia. Since the EAP is not properly incorporated into the Fire and Rescue Department of Malaysia, it is an open question how the department manages psychological issues at the individual level. Firefighters may not face as high emotional burden as healthcare workers, but as human beings, they need some psychological care. Therefore, the psychological care subdimension of the SSI should be maintained.

This article presents 16 culturally tailored subdimensions of the SSI and the five formative items, within the HC scale that should be used to measure satisfaction and happiness among firefighters. Each formative subdimension of the SSI has its own weight, simulating real phenomena in determining the final SSI score of in-service firefighters. This work has practical implications for other uniformed organizations. They can use the subdimensions as a solid framework to measure their own employees. We believe that this article gives a comprehensive framework to researchers for analyzing a complex model with multiple first- and secondorder independent variables and regressing on a formative dependent variable. In the light of hope, this article will be able to guide researchers to develop and validate new or adopted constructs or to test theories successfully. The SSI and $\mathrm{HC}$ scales are a vital contribution to assessing firefighters' satisfaction and happiness levels at work. Both tools are statistically reliable and valid. Now they are ready to fly high and be heroes.

\section{Data Availability}

The data used to support the findings of this study are included within the supplementary information file(s).

\section{Conflicts of Interest}

The authors declare that there are no conflicts of interest. 


\section{Acknowledgments}

This study was financially supported by Publication Grant of Universiti Kebangsaan Malaysia (GP-2020-K016553).

\section{Supplementary Materials}

The data were generated as part of research activity in FRDM to measure and enhance employee satisfaction and happiness at work among firefighters. (Supplementary Materials)

\section{References}

[1] Compendium of Physical Activities, 11-occupation, https:// sites.google.com/site/compendiumofphysicalactivities/ Activity-Categories/occupation, 2011.

[2] Malaysia Occupational Safety and Health Act 1994 (Act 514).

[3] S. McLeod, Maslow's Hierarchy of Needs, https://www. simplypsychology.org/maslow.html, 2020.

[4] F. Herzberg, B. Mausnes, R. O. Peterson, and D. F. Capwell, Job Attitudes; Review of Research and Opinion, Psychological Service of Pittsburgh, Pittsburgh, PA, USA, 1957.

[5] P. C. Smith, L. M. Kendall, and C. L. Hulin, The Measurement of Satisfaction in Work and Retirement: A Strategy for the Study of Attitudes, Rand McNally Psychology Series, Skokie, IL, USA, 1969.

[6] P. Warr, The Psychology of Happiness, Routledge, Milton Park, UK, 1 edition, 2019.

[7] F. Faul, E. Erdfelder, A. Buchner, and A.-G. Lang, "Statistical power analyses using $G *$ Power 3.1: tests for correlation and regression analyses," Behavior Research Methods, vol. 41, no. 4, pp. 1149-1160, 2009.

[8] C. M. Ringle, S. Wende, and J.-M. Becker, SmartPLS 3, http:// www.smartpls.com, 2015.

[9] W. W. Chin, B. L. Marcelin, and P. R. Newsted, "A partial least squares latent variable modeling approach for measuring interaction effects: results from a Monte Carlo simulation study and an electronic-mail emotion/adoption study," Information Systems Research, vol. 14, 2003.

[10] J. C. Anderson and D. W. Gerbing, "Structural equation modeling in practice: a review and recommended two-step approach," Psychological Bulletin, vol. 103, no. 3, pp. 411-423, 1988.

[11] J. F. Hair, J. J. Risher, M. Sarstedt, and C. M. Ringle, "When to use and how to report the results of PLS-SEM," European Business Review, vol. 31, no. 1, pp. 2-24, 2019.

[12] T. Ramayah, J. Cheah, F. Chuah, H. Ting, and M. Ali Memon, "Partial least squares structural equation modeling (PLSSEM) using SmartPLS 3.0: an updated and practical guide to statistical analysis," in Practical Assessment, Research and Evaluation, Pearson Malaysia Sdn Bhd, Kuala Lumpur, Malaysia, 2 edition, 2018.

[13] N. Kock and G. S. Lynn, "Lateral collinearity and misleading results in variance-based SEM: an illustration and recommendations," Journal of the Association for Information Systems, vol. 13, no. 7, pp. 546-580, 2012.

[14] N. Kock, "Common method bias in PLS-SEM: a full collinearity assessment approach," International Journal of E-Collaboration, vol. 11, no. 4, pp. 1-10, 2015.

[15] J. Henseler, C. M. Ringle, and M. Sarstedt, "A new criterion for assessing discriminant validity in variance-based structural equation modeling," Journal of the Academy of Marketing Science, vol. 43, no. 1, pp. 115-135, 2015.
[16] G. Franke and M. Sarstedt, "Heuristics versus statistics in discriminant validity testing: a comparison of four procedures," Internet Research, vol. 29, no. 3, pp. 430-447, 2019.

[17] J. F. Hair, G. T. M. Hult, C. M. Ringle, and M. Sarstedt, A Primer on Partial Least Squares Structural Equation Modeling (PLS-SEM), Sage, California, MA, USA, 2 edition, 2017.

[18] Canadian Centre for Occupational Health and Safety, Mental Health - Psychosocial Risk Factors in the Workplace: OSH Answers, Canadian Centre for Occupational Health and Safety, Hamilton, Ontario, 2011, https://www.ccohs.ca/ oshanswers/psychosocial/mentalhealth_risk.html.

[19] International Labour of Organization, Medical and Health Surveillance, International Labour of Organization, Geneva, Switzerland, 2004, https://www.ilo.org/ legacy/english/protection/safework/cis/products/safetytm/ chemcode/13.htm.

[20] A. Diamantopoulos and J. A. Siguaw, "Formative versus reflective indicators in organizational measure development: a comparison and empirical illustration," British Journal of Management, vol. 17, no. 4, pp. 263-282, 2006.

[21] W. Wu Wei, "Linking Bayesian networks and PLS path modeling for causal analysis," Expert Systems with Applications, vol. 37, pp. 134-139, 2010.

[22] J. Cohen, Statistical Power Analysis for the Behavioural SciencesLawrence Erlbaum Associates, Hillsdale, NJ, USA, 1988.

[23] R. F. Falk and N. B. Miller, A Primer for Soft Modeling, University of Akron Press, Akron, OH, USA, 1992.

[24] J. Cohen, “A power primer," Psychological Bulletin, vol. 112, no. 1, pp. 155-159, 1992.

[25] W. W. Chin, "Bootstrap cross-validation indices for PLS path model assessment," in Handbook of Partial Least Squares: Concepts, Methods and Applications, V. Esposito, W. W. Chin, J. Henseler, and H. Wang, Eds., Springer-Verlag, Berlin Heidelberg, pp. 83-97, 2010.

[26] K. C. Mathias, E. Graham, D. Stewart, and D. L. Smith, "Decreased pulmonary function over 5 Years in US firefighters," Journal of Occupational and Environmental Medicine, vol. 62, no. 10, pp. 816-819, 2020.

[27] NFPA, "Deadliest fires or explosions in the world," NFPA, Quincy, MA, USA, 2021, https://www.nfpa.org/News-andResearch/Data-research-and-tools/US-Fire-Problem/ Catastrophic-multiple-death-fires/Deadliest-fires-orexplosions-in-the-world.

[28] R. T. Yi, F. W. Mahyuddin, and N. Mahyuddin, "The analysis of fire losses and characteristics of residential fires based on investigation data in Selangor, 2012-2014," in Proceedings of the MATEC Web of Conferences, Kuala Lumpur, Malaysia, January 2016.

[29] I. Rosnah, A. Asnarulkhadi, A. Ismail, and A. Ashrul Reizal, "Exploring the critical elements of physical activities best tailoring for enhancement of fitness level for firefighters," 2021.

[30] C. Lee, E. K. Phillips, R. Jablonski et al., "Firefighters with interstitial lung disease: an emerging occupational exposure," in Proceedings of the American Thoracic Society International Conference, Philadelphia, PA, USA, May 2020.

[31] International Association of Fire Chiefs, Mental Health: Playing with Fire, International Association of Fire Chiefs, Fairfax, VA, USA, 2020, https://www.iafc.org/docs/defaultsource/1assoc/ichiefsmag_2020summer.pdf. 
[32] International Labour Organization, Workplace Stress: A Collective Challenge, ILO Publications, Geneva, Switzerland, 1 edition, 2016.

[33] E. E. Kossek and K. Lee, Work-Family Conflict and Work-Life Conflict the Growing Societal Importance of Work, https:// oxfordre.com/business/view/10.1093/acrefore/9780190224851. 001.0001/acrefore-9780190224851-e-52, 2017.

[34] T. D. Smith, D. M. DeJoy, M. A. Dyal, and G. Huang, "Impact of work pressure, work stress and work-family conflict on firefighter burnout," Archives of Environmental \& Occupational Health, vol. 74, no. 4, pp. 215-222, 2019. 